\title{
TINJAUAN PENGARUH VARIASI BEBAN DAN PUTARAN TERHADAP KINERJA MESIN DIESEL 4 TAK 1 SILINDER DENGAN PEMANASAN DAN MEDAN MAGNET DI SALURAN BIODIESEL
}

\author{
MUHAMAD SIRAJUDIN \\ Politeknik Negeri Sriwijaya Palembang \\ msirajudin49@gmail.com
}

\section{Abstrak}

Bahan bakar Bio menjadi salah satu sumber alternatif terbarukan untuk mesin diesel dalam mengatasi permasalahan di bidang otomotif, karena ketersediaan bahan bakar fosil minyak bumi yang semakin menipis. Untuk pembakaran yang sempurna bahan bakar tersebut memerlukan perlakuan tertentu sebelum memasuki ruang bakar. Kegiatan penelitian yang bertujuan untuk mendapatkan hasil pembakaran yang sempurna dan menghasilkan kinerja yang optimal pada mesin diesel khususnya dengan bahan bakar bio telah banyak dilakukan, baik pada mesin diesel 4 tak satu silinder maupun pada mesin diesel 4 tak multi silinder, antara lain yaitu: pemanasan awal, menyebabkan bahan bakar akan menjadi lebih reaktif untuk bereaksi dengan oksigen pada proses pembakaran sehingga proses pembakaran menjadi lebih sempurna. Optimalisasi proses pembakaran dengan teknik medan elektro magnet, medan magnet di gunakan untuk menggetarkan (meresonansi) bahan bakar dan terjadilah ionisasi yang diperlukan agar bahan bakar dapat dengan mudah mengikat oksigen selama proses pembakaran, sehingga campuran bahan bakar dan oksigen dapat terbakar dengan sempurna. Dengan proses pembakaran yang sempurna, maka akan menghasilkan prestasi atau kinerja mesin diesel yang optimal. Mengintegrasikan kedua teknik optimalisasi proses pembakaran tersebut diatas dan memposisikan kedua proses tersebut lebih mendekati ruang bakar tentu akan lebih meningkatkan prestasi atau kinerja pada mesin diesel dengan bahan bakar biodiesel. 


\section{Abstract}

Bio fuel is one of the renewable alternative sources for diesel engines in overcoming the problems in the automotive field, due to the increasingly depleted availability of petroleum fossil fuels. For perfect combustion the fuel requires certain treatment before entering the combustion chamber. Research activities aimed at obtaining perfect combustion results and producing optimum performance on diesel engines especially with bio fuel has been widely practiced, either on 4-stroke diesel engine or one cylinder diesel 4 non-cylinder, among others, namely: preheating, causing the fuel to become more reactive to react with oxygen in the combustion process so that the combustion process becomes more perfect. Optimization of combustion process with electromagnetic field technique, magnetic field is utilized to vibrate (resonance) fuel and ionisation takes place so that the fuel can readily bind oxygen during the combustion process, so that the mixture of fuel and oxygen can burn completely. With a perfect combustion process, it will produce the performance or performance of the optimal diesel engine. Integrates both combustion process optimization techniques above and positioning two process the more close to the combustion chamber certain will further improve achievement or performance on a diesel engine with biodiesel fuel.

Keywords : Biodiesel, heater, electromagnetic field, diesel engine performance.

\section{PENDAHULUAN}

\section{Latar Belakang}

Penggunaan bahan bakar minyak semakin hari semakin meningkat. Bahan Bakar Minyak (BBM) berperan sangat penting dalam perkembangan teknologi, terutama dalam teknologi industri dan otomotif. Minyak bumi merupakan sumber energi utama dan sumber devisa negara. Namun demikian, cadangan minyak bumi yang dimiliki Indonesia jumlahnya terbatas. Sedangkan bahan bakar minyak merupakan salah satu sumber daya alam yang tidak dapat diperbaharui. Dari hasil kajian Departemen Energi dan 
Sumber Daya Mineral (ESDM) paling mutakhir bahwa jika tidak ada penemuan sumber minyak baru, maka cadangan minyak kita hanya cukup sampai 18 tahun kedepan, gas bumi masih 60 tahun, dan batu bara masih 150 tahun.

Kenaikan harga minyak mentah dunia yang mencapai titik tertinggi pada pertengahan tahun 2008 menghantam segala sendi perekonomian dan kehidupan masyarakat Indonesia.

Biodiesel merupakan bahan yang sangat potensial digunakan sebagai pengganti bahan bakar diesel. Hal ini disebabkan karena bahan bakunya berasal dari minyak nabati dapat diperbaharui, dan dapat dihasilkan secara priodik. Biodiesel juga merupakan bahan bakar yang ramah lingkungan, tidak mengandung belerang sehingga dapat mengurangi kerusakan lingkungan yang diakibatkan oleh hujan asam (rain acid). Biodiesel sebagai pengganti solar mempunyai beberapa keuntungan, di antaranya adalah lebih bersih dalam emisi gas buang, pelumasan yang lebih baik, dan tidak diperlukannya modifikasi mesin.

Biodiesel mempunyai flash point lebih tinggi dari pada solar, sehingga tidak mudah terbakar, sifat lain dari biodiesel adalah mempunyai Cetane number dan Viskositas lebih tinggi dibanding solar nilai dari sifat karakteristik tersebut berpengaruh kepada proses pembakaran pada mesin diesel.

Ketidak sempurnaan proses pembakaran menyebabkan kinerja mesin menjadi tidak optimal biasanya terjadi karena: jumlah bahan bakar dalam ruang bakar yang tidak sesuai dengan kebutuhan, proses penginjeksian (pengkabutan) kualitas bahan bakar yang kurang baik atau kurang baiknya proses pencampuran bahan bakar dengan udara dalam ruang bakar, merupakan masalah yang sering dijumpai dalam mesin diesel. 
Tabel 1. Sifat fisika/kimia biodiesel

\begin{tabular}{ccc}
\hline Sifat Fisika/Kimia & Biodiesel & Solar \\
\hline \hline Komposisi & Ester alkil & Hidrokarbon \\
Densitas, g/ml & 0,8624 & 0,8750 \\
Viscositas, cSt & 5,55 & 4,6 \\
Titik kilat, ${ }^{\circ} \mathrm{C}$ & 172 & 98 \\
Angka setana & 62,4 & 53 \\
Energi yang dihasilkan & $40,1 \mathrm{MJ} / \mathrm{kg}$ & $45,3 \mathrm{MJ} / \mathrm{kg}$ \\
\hline
\end{tabular}

Sumber : Internasional Biodiesel, 2001

Untuk menghasilkan proses pembakaran yang sempurna didalam ruang bakar mesin diesel yang mengunakan bahan bakar biodiesel diperlukan suatu perlakuan pada biodiesel sebelum masuk ke ruang bakar antara lain: pemanasan yang akan berpengaruh pada visicositas,dan titik nyalanya. Pemanasan awal bahan bakar di perkirakan dapat meningkatkan unjuk kerja motor bakar. Hal ini dimungkinkan karena dengan memberikan panas awal pada bahan bakar, maka bahan bakar akan menjadi jenuh dan mengakibatkan suhu bahan bakar mendekati titik nyalanya, sehingga mudah terbakar, yang berarti pemanasan awal dapat memperbaiki pembakaran.

Ionisasi medan magnet diperlukan agar bahan bakar dapat dengan mudah meningkat oksigen selama proses pembakaran, sehingga campuran bahan bakar dan oksigen dapat terbakar dengan sempurna. Dengan pembakaran yang lebih sempurna, maka dapat menghemat konsumsi bahan bakar (PITHE).

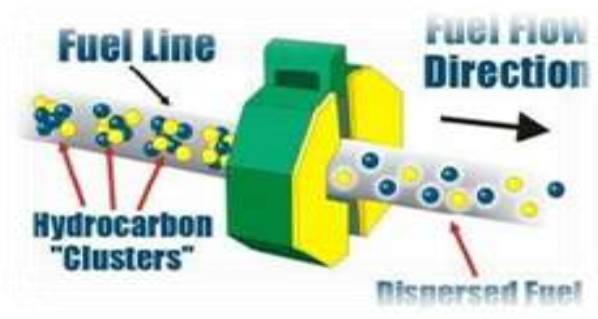

Gambar1. Proses Ionisasi Magnetik 


\section{METODOLOGI PENELITIAN}

\subsection{Jenis dan Metode Penelitian}

Jenis dan metode penelitian yang digunakan pada penulisan karya tulis ilmiah ini adalah studi literatur. Dimana, bahan-bahan yang di ambil berupa:

1. Jurnal penelitian mengenai aplikasi pengaruh temperatur pemanasan awal biodiesel terhadap kinerja mesin diesel.

2. Jurnal penelitian mengenai pegaruh medan magnet terhadap konsumsi bahan bakar dan kinerja motor bakar.

3. Jurnal penelitian Uji Performance Mesin Diesel Menggunakan Biodiesel Dari Minyak Goreng Bekas

\subsection{Objek dan Subjek Permasalahan}

Subjek permasalahan jurnal tinjauan ini adalah aplikasi biodiesel yang merupakan salah satu alternatip sumber EBT sebagai bahan bakar mesin diesel 4 tak satu silinder. Dan yang menjadi objek permasalahan dalam karya tulis ini ialah adalah integrasi dua teknik optimalisasi proses pembakaran pada saluran bahan bakar biodiesel serta pengaruhnya terhadap kinerja mesin diesel 4 tak 1 silinder.

\subsection{Sumber Data}

Data sekunder merupakan sumber data yang di gunakan pada penulisan jurnal ini. Data tidak diperoleh secara langsung dari sumbernya (data primer), misalnya wawancara dan tinjauan kelapangan (observasi). Namun data sekunder ini diperoleh dari jurnal-jurnal penelitian terdahulu yang berhubungan dengan uji kinerja dan optimalisasi proses pembakaran pada mesin diesel secara umum dan khususnya dengan bahan bakar biodiesel. 


\subsection{Metode Pengumpulan data}

Studi pustaka merupakan metode yang digunakan pada penulisan karya ilmiah ini,baik yang berasal dari informasi dokumen tertulis, elektronik, foto, gambar, yang berhubungan dan bersifat memperkaya data yang dibutuhkan untuk proses penulisan.

\subsection{Teknik Pengumpulan Data}

Adapun teknik pengumpulan data dalam penulisan karya ilmiah ini adalah teknik membaca, mencatat, dan menganalisis. Dimana bahan pustaka yang telah dikumpulkan dibaca terlebih dahulu kemudian mencatat bagian-bagian penting dari bahan pustaka sekaligus mengutip pendapat para ahli yang relevan dengan penelitian. Selanjutnya, data-data tersebut di analisis sehingga diperoleh sekumpulan data yang memperkuat argumen penulis mengenai perancangan alat uji kinerja mesin dan teknik optimalisasi proses pembakaran yang akan dilakukan serta menintegrasikan dua teknik yang mengarah kepada penigkatan kinerja mesin diesel berbahan bakar biodiesel.

\section{HASIL DAN PEMBAHASAN}

Upaya dalam penelitian dan pengembangan sumber energi alternatif sudah cukup banyak dilakukan antara lain pemanfaatan minyak nabati sebagai pengganti solar. Namun di ketahui beberapa kekurangan dari minyak nabati, jika digunakan secara langsung pada mesin dapat menyebabkan kerusakan pada mesin, karena menyebabkan terbentuk senyawa deposit pada injector. Selain itu juga visikositas yang lebih tinggi mengangu peroses pengkabutan oleh injector dan menyebabkan peroses pembakaran tidak sempurna.Usaha untuk mengubah karakteristik minyak nabati sehingga dapat mengkonversi 
minyak nabati kedalam bentuk metil ester asam lemak (FAME:Fatty acid metil ester) melalui proses esterefikasi atau Transesterifikasi yang lebih dikenal dengan "Biodiesel".

Biodiesel mempunyai flash point lebih tinggi dari pada solar, sehingga tidak mudah terbakar, sifat lain dari biodiesel adalah mempunyai Cetane number dan Viskositas lebih tinggi dibanding solar. Disamping itu biodiesel tidak mengandung sulfur dan senyawa benzene yang karsinogenik sehingga biodiesel merupakan bahan bakar yang lebih bersih dan lebih mudah ditangani dibandingkan dengan solar, serta sifat pelumasan yang lebih baik dibandingkan solar.

Secara kimia biodiesel termasuk dalam golongan mono alkyl ester atau metyl ester dengan panjang rantai karbon antara 12 sampai 20, sedangkan petroleum diesel (solar) mempunyai komponen utama adalah hidrokarbon. Karena mempunyai sifat kimia dan fisika yang serupa dengan solar maka biodiesel memungkinkan untuk digunakan langsung pada mesin diesel atau dicampur dengan solar tanpa perlu memodifikasi mesin.

Mesin diesel atau motor bakar sejenis,dikatakan bekerja dengan peforma yang baik jika dapat menghasilkan daya yang besar, konsumsi bahan bakar rendah, dan kandungan polutan dari gas buang kecil, kondisi ini hanya dapat tercapai apabila proses pembakaran pada mesin diesel tersebut terjadi secara sempurna.

Selama ini telah dilakuakan beberapa penelitian untuk mendapatkan peforma mesin diesel yang lebih baik antara lain : Mahasiswa magister teknik universitas diponegoro melakukan penelitian dengan tujuan meningkatkan kinerja mesin diesel melalui penyempurnaan proses pembakaran dengan cara 
pemanasan terhadap bahan bakar sebelum dinjeksikan ke dalam ruang bakar, dengan tujuan untuk menurunkan viskositasnya sehingga setelah diinjeksikan ke dalam ruang bakar dapat membentuk butiran-butiran yang lebih halus dan menghasilkan campuran bahan bakar-udara yang lebih homogen. Dengan menurunkan viskositas bahan bakar campuran antara solar dan biodiesel untuk mesin diesel putaran konstan, menunjukan dengan menambahkan pemanas bahan bakar dapat menaikan efisiensi mesin Diesel.

Dalam kajian ekperimen ini mencoba membandingkan pengaruh temperatur solar dan biodiesel terhadap kinerja mesin diesel yaitu konsumsi bahan bakar, BSFC dan efisiensi termal. Pemanasan bahan bakar baik solar maupun biodiesel dilakukan mulai dari temperatur normal $33{ }^{\circ} \mathrm{C}$ sampai temperatur $70{ }^{\circ} \mathrm{C}$ kemudian dilakukanlah pengujian berat jenis, viskositas dan selanjutnya pada temperatur ini diujikan pada mesin diesel untuk melihat bagaimana perubahan yang terjadi pada unjuk kerja mesin diesel tersebut, sehingga diketahui pada temperatur berapa solar dan biodiesel akan memberikan performa mesin diesel yang maksimum. Dari hasil penelitian ini disimpulkan bahwa Kenaikan temperatur bahan bakar biodiesel maupun solar akan mempengaruhi konsums, bsfc, dan efisiensi thermal mesin diesel,bila temperaturnya dinaikan maka konsumsinya akan cendrung menurun,begitu juga bsfcnya,tetapi efisiesnsi termalnya cendrung meningkat peningkatan ini hanya sampai pada tempratur $70^{\circ} \mathrm{C}$ untuk biodiesel, sedangkan untuk solar pada tempratur $60^{\circ} \mathrm{C}$. Bila bahan bakar temperaturnya masih dinaikan justru efisiensinya akan menurun.

Dalam penelitian ini mengunakan mesin diesel dong feng 1 silinder direct injektion putaran konstan ini efisiensi termal terbaik biodiesel adalah 21,3\% pada temperatur $700 \mathrm{C}$ dengan BSFC $11 \%$, pada kondisi ini penurunan 
konsumsi bahan bakar sebesar 8\% dbandingkan dengan kondisi pada tempratur $33^{\circ}$.Sedangkan efisiensi termal terbaik solar adalh $23,7 \%$ pada $60^{\circ} \mathrm{C}$ dengan $\mathrm{BSF} 4 \%$.

Meneliti pengaruh pemanasan awal bahan bakar solar terhadap peforma dan konsumsi bahan bakar mesin diesel. Hasil penelitian nya adalah Nilai viskositas dan densitas bahan bakar solar menurun dengan meningkatnya temperatur bahan bakar tersebut. Setelah dilakukan pengujian pada mesin diesel. Konsumsi bahan bakar yang paling irit terjadi pada temperatur $50^{\circ} \mathrm{C}$ pada putaran mesin 1000 (rpm), sedangkan konsumsi bahan bakar yang paling boros terjadi tanpa pemanasan pada putaran mesin 2000 (rpm). Performa mesin diesel juga mengalami peningkatan pada torsi. dan daya setelah bahan bakar solar dipanaskan.

Dalam penelitianya :Pengaruh Medan Magnet Terhadap Konsumsi Bahan Bakar dan Emisi Gas Buang pada Motor Diesel Dengan Bahan Bakar Biodiesel Dari hasil penelitian di dapat : 1) Konsumsi bahan bakar terendah terjadi pada pengujian yang menggunakan magnet permanen pada putaran 800rpm yaitu sebesar $185 \mathrm{ml}$,berbeda dengan tanpa magnet konsumsi bahan bakar tertinggi pada putaran $800 \mathrm{rpm}$ adalah $210 \mathrm{ml}$. 2) Emisi gas buang terendah terjadi pada pengujian yang menggunakan $800 \mathrm{rpm}$ sedangkan emisi gas buang tertinggi terjadi pada pengujian yang menggunakan putaran mesin $2000 \mathrm{rpm}$. 3) Emisi gas buang tertinggi terjadi pada senyawa NO ( Nobelium ) yaitu sebesar 163,3 PPM,sedangkan untuk emisi gas buang terendah terjadi pada senyawa SO2 (Gas Belerang Monoksida ) yaitu sebesar12 PPM.

Meneliti Pengaruh Medan Magnet Terhadap Efisiensi Bahan Bakar dan Unjuk Kerja Mesin Suzuki Smash 110 cc dalam penelitian ini menghasilkan 
bahwa: A) pengaruh bahan bakar dengan medan magnet berpengaruh terhadap unjuk kerja mesin, B) hasil penelitian dengan variasi tanpa medan magnet 0, 0286 tesla rpm 1750 adalah $0.168 \mathrm{~kg} / \mathrm{jamPs}$, dengan medan magnet 0.0190 tesla rpm 1750 adalah $0,169 \mathrm{~kg} / \mathrm{jamPs}$, sedangkan variasi medan magnet 0.0143 tesla rpm 1750 adalah $0,169 \mathrm{~kg} / \mathrm{jamPs}$. Jadi hasil pemanasan bahan bakar yang paling efisiensi dari hasil penelitian ini adalah penggunaan medan magnet 0.0286 tesla. Sedangkan daya yang dihasilkan pada putaran mesin yang sama (1750 rpm) yaitu variasi tanpa pemanasan 42,19 PS, variasi medan magnet 0.0286 tesla 47,02 PS, variasi medan magnet 0.0190 tesla 46,92 PS, variasi medan magnet 0.0143 tesla 46,81 PS. Jadi dari hasil pemakaian medan magnet pada bahan bakar yang menghasilkan daya terbaik adalah variasi medan magnet 0.0286 tesla. C) Hasil reaksi medan magnet pada bahan bakar yang paling efektif dari hasil penelitian ini adalah penggunaan medan magnet yang paling besar yaitu 0.0286 tesla. D) Sedangkan hasil yang kurang efektif dari hasil penelitian ini adalah penggunaan medan magnet yang paling kecil yaitu 0.0143 tesla.

Berdasarkan beberapa uraian penelitian diatas dapat ditarik benang merah dalam arti kertekaitan bahwa teknik pemanasan dan teknik medan elektromagnet pada bahan bakar biodiesel sangat berpengaruh pada proses pembakaran yang terjadi pada ruang bakar yang berakibat pada meningkatnya kinerja dan menurunya emisi gas buang mesin atau motor bakar diesel walaupun hasilnya belum maksimal (rata rata kurang dari 26\%). Oleh karena itu mengintegrasikan dari kedua teknik perlakuan tersebut diatas diharapkan akan menghasilkan kinerja mesin diesel dengan bahan bakar biodiesel yang seoptimal. 


\section{KESIMPULAN}

Pemakaian teknik pemanasan awal pada bahan bakar diesel untuk optimalisasi proses pembakaran terbukti efektif karena mampu meningkatkan kinerja mesin diesel.

Perlakuan teknik memberikan pengaruh medan magnet pada bahan bakar diesel adalah efektif karena menghasilkan kinerja terutama gas buang yang baik pada mesin diesel.

\section{DAFTAR PUSTAKA}

Fajar, B., \& Suryo, T. (2010). Perbandingan Pengaruh Temperatur Solar Dan Biodiesel Terhadap Performa Mesin Diesel Direct Injection Putaran Konstan. Prosiding SNST Fakultas Teknik, 1(1).

Hidayatulloh, S., \& Suyatno, A. (2015). Pengaruh Medan Magnet Terhadap Konsumsi Bahan Bakar Dan Emisi Gas Buang Pada Motor Diesel Dengan Mengunakan Bahan Bakar Biodiesel. Widya Teknika, 23(1).

Janu Prasetyo, Gatut Rubiono, Bunawi (2017)

"Pengaruh Medan Magnet Terhadap Efisiensi Bahan Bakar dan Unjuk Kerja Mesin” Jurnal V-Mac, Vol 2 No 1: 13-17, 2017, ISSN 2528-0112 (online)

Rosyadi, I. (2014). Analisa Pengaruh Pemanasan Awal Bahan Bakar Solar terhadap Performa dan Konsumsi Bahan Bakar pada Mesin Motor Diesel Satu Silinder.

Sahbana, M. A., \& Fuhaid, N. (2013). Pengaruh Pemanasan Awal dan Medan Elektromagnet pada Biodiesel terhadap Daya dan $\begin{array}{llllll}\text { Kepekatan Gas Buang pada } & \text { Motor } & \text { Diesel } 4 & \text { Tak } & 4\end{array}$ Silinder. PROTON, 5(1).

Suwarsono, WP., Gani, I.Y, dan Kusyanto, 2008, “ Sintesis Biodiesel dari Minyak Biji Ketapang yang Berasal dari Pohon Ketapang Yang Tumbuh di Kampus UI Depok “, Valensi, vol.1, no.2, 44-52. 
Sugiarto,B., Setiawan dan Suryantoro, (2005), Studi Emisi dan Heat Release Biodiesel Minyak Sawit Dan Minyak Jarak Pada Mesin Diesel Indirect Injection, Jurnal Teknologi, Vol. 2, PP.101-107

Pulkrabek, w.w (1997).Engineering Fundamentals of the international combustion engine (No.621.43 P8). 